\title{
El directo ético y el directo patético en los informativos de televisión
}

\section{Ethical and pathetic live for television news broadcasting}

\author{
Concha Mateos \\ Universidad Rey Juan Carlos \\ concepcion.mateos@urjc.es
}

\begin{abstract}
Resumen
La imagen puede engañar incluso mostrando fragmentos de lo real. La elaboración del discurso audiovisual supone operaciones simbólicas que operan sobre la huella que lo real deja en el registro tecnológico convirtiéndolo en un signo, sujeto a todos los artificios y convenciones de los signos. El discurso informativo de las cuatro cadenas de televisión estudiadas en esta comunicación genera evidencias sobre cómo el montaje audiovisual subvierte a veces los principios básicos de la ética informativa. El análisis realizado surte de un cuadro de categorías que permite evaluar éticamente los distintos usos del directo en los informativos.
\end{abstract}

Palabras Clave: Informativos televisión, directo, ética informativa.

\begin{abstract}
Images can deceive, even when they show traces from the real world. Making audiovisual discourses involves symbolic dealings that affect the tracks produced by the technological recording. The images registered in that process become signs and that signs are subjected to all artful devices and conventions that signs entail. For this article, I have analysed the discourse of audiovisual news from four television channels. This provides strong proof about how images editing can subvert deeply the essential principles of news professional ethics. This analysis provides a taxonomical table that enable us to distinguish, classify and evaluate the different ways of live reporting news.
\end{abstract}

Keywords: TV news, live reporting, professional ethics. 


\section{INTRODUCCIÓN}

"El telediario, en su fascinación por el «espectáculo del acontecimiento» ha desconceptualizado la información y la ha ido sumergiendo progresivamente en la ciénaga de lo patético. Insidiosamente ha establecido una especie de nueva ecuación de la información que podía formularse así: si la emoción que usted siente viendo el telediario es verdadera, la información es verdadera"

Ignacio Ramonet, La tiranía de la comunicación

La información televisiva es una vía mediada de la persona con lo real, una forma indirecta de experiencia de lo que ocurre en el mundo. Es un recurso con el que acercarse al conocimiento de lo real: un texto. En televisión es audiovisual y constituye lo que llamamos la realidad (González Requena, 1998 y 1989, p. 7).

Designamos como realidad al discurso sobre lo real. Distinguimos pues la realidad de lo real porque aquella es una formulación humana, un enunciado sobre lo real, un producto afectado ineludiblemente por el proceso mediante el cual es producido. Este constructo (la realidad) conserva una cierta huella de lo real y siempre imborrables huellas de su proceso de producción.

El análisis que aquí se presenta trabaja sobre un texto de este tipo, el que es observado desde la interrogación sobre sus rasgos éticos.

Nos dice la Real Academia Española que lo ético es lo recto, también lo que es conforme a las obligaciones del hombre, según la moral. La ética comprende pues el conjunto de principios que rigen el comportamiento humano. En una perspectiva individual, la ética implica el criterio o las reglas de comportamiento en las que se basa la vida de cada persona y el vector que rige su motivación (el placer, la felicidad, la dignidad, la justicia, etc.). Estas reglas conforman códigos, que llamamos códigos éticos, y que dependen o responden a las creencias religiosas, normas sociales, contextos históricos y filosofía económicas de cada sociedad (Aranguren, 1996; Matelski, 1992).

Nuestro objetivo en este trabajo es dilucidar las aplicaciones éticas de una técnica específica de edición (el directo) utilizada en los informativos televisivos. Precisamos para ello identificar la conexión, el espacio de interacción, entre información televisiva y ética. ¿Dónde localizamos esa área de intersección de ambas?

$\mathrm{Al}$ proponerse a las personas como complemento o sustituto de su experiencia directa en lo real, la ética del discurso informativo audiovisual, la ética de la realidad que construyen los informativos de televisión, se localiza en la forma en que este producto (de orden simbólico) modela la relación de las personas con lo real. ¿De qué manera informativa la experiencia televisiva suple o complementa el conocimiento que los espectadores pueden obtener por experiencia directa?

En la cualidad de esa relación sitúa este trabajo su objeto de interés: el modo en 
que las noticias televisivas promueven la relación de los espectadores con lo real. ¿Qué clase de relación con el mundo real proponen las noticias de televisión a los espectadores cuando utilizan el directo? ¿Es una relación ética?

Al tratarse de una relación mediada, el espectador queda ajeno a los mecanismos de comprobación (salvo en casos singulares en los que el espectador pueda ser el objeto de las noticias). De tal modo, nuestra indagación se orientará hacia la verdad de esa relación. Y, como señala González Requena (2008, p. 8), eso supone que situamos la cuestión de la verdad en "su territorio esencial: el de la ética".

\section{EL DIRECTO TELEVISIVO COMO PARADIGMA DE LA EFICIENCIA INFORMATIVA}

¿Qué entiendo por directo y por qué me ciño a él? La especificidad narrativa del directo implica la coincidencia de tres tiempos:

- El tiempo del acontecimiento

- El tiempo de la enunciación del relato

- El tiempo de la lectura ${ }^{1}$.

En la retransmisión en directo las cosas pasan mientras se relatan y a la vez que el receptor lee el relato.

Razones que motivan mi atención específica al directo:

1. Porque la televisión ha impuesto un dominio sobre los otros medios.

2. Y porque lo ha hecho blandiendo como bandera de especificidad un rasgo propio que le ha sido exclusivo durante largo tiempo: el directo audiovisual.

La televisión ha ostentado como característica diferencial la posibilidad del directo audiovisual durante más de medio siglo (era imposible para la prensa, la radio podía ofrecerlo, pero sin imágenes, y solo ahora, gracias a la convergencia mediática, el ordenador, medio que no es la pantalla del aparato de televisión, puede ofrecerlo).

El directo televisivo ha supuesto pues un valor añadido (García de Castro, 2007, pp. 11-13), una ventaja competitiva de un medio, la televisión, que se ha confirmado como preferente en las pautas de consumo mediático de la población en todas las estadísticas del mundo capitalista

1 Cebrián Herreros en Géneros informativos audiovisuales (1992) habla de 4 tiempos: el del suceso, el de la elaboración narrativa, el de la difusión y el de la recepción-lectura. En un esquema clásico de comunicación serían: el del referente (suceso), el del emisor (enunciación) y el del receptor (lectura) y, coincidiendo el del emisor y el del receptor, queda implícito el de distribución a través del canal. Por eso solo hablo de tres tiempos. 
Además, el directo en televisión ha consolidado un áurea de valor mítico para la inmediatez como técnica de realización informativa (Dayán, 1992), especialmente a partir de los acontecimientos del 11-S de 2001.

Que la televisión fuese la estrella mediática que podía ofrecer el directo audiovisual en exclusiva, que fuese la más deseada y que el directo fuera ascendido a la condición de máximo valor informativo por la inmediatez que proporciona, determinaron lo que en un trabajo anterior llamé la dominancia televisiva (Mateos, 2004).

Esta dominancia televisiva comporta una serie de efectos secundarios descritos ampliamente por una larga tradición crítica de análisis de la televisión que va desde Postman (2001) a Ramonet (1999), pasando por la mutación ontológica prefigurada por Sartori (1998) o la fagocitación espectacular descrita con detalle por González Requena (1988).

¿En qué se concreta esa dominancia televisiva? En que la televisión:

- Domina en el consumo. Es la más -y con frecuencia la única- fuente de información para gran parte de la ciudadanía.

- Domina las agendas (Ramonet, 1999). Condiciona las agendas de otros medios, impone preferencia sobre lo inmediato, lo presente.

- Domina el componente visual (Sartori, 1998). Promueve la primacía de lo visual sobre lo abstracto. Lo visual es la característica diferencial de la televisión y al ser ella dominante en los dos parámetros anteriores, extiende esta dominancia a los aspectos destacables de los acontecimientos: el componente visual prima sobre el componente verbal y abstracto en el discurso informativo que ella promueve.

- Domina la fijación de un modo particular de consumo mediático como modo general. Prioriza una relación con los acontecimientos en clave de entretenimiento y de emoción (Postman, 2001).

\section{DIRECTO, ÉTICA E IDEOLOGÍA DE LOS MEDIOS}

Esta especificidad que exhibe como bandera el medio dominante es la raíz de una ideología informativa, la ideología del directo (Ramonet, 1999). La forma de hacer relatos, especialmente relatos informativos, que los medios de comunicación (bajo la dominancia televisiva) apuntalan día a día provoca que cristalicen creencias que se articulan generando sistemas de creencias, es decir, ideologías, marcos de comprensión e interpretación, de ahí nace lo que González Requena identifica y caracteriza como la ideología de los medios de comunicación (1989, pp. 13-15), responsable de la vigencia de la idea de que existe y es posible la objetividad en el discurso, como si este pudiera devolver los hechos tal como son.

Dado que las normas éticas requieren y se soportan sobre un marco de valores socialmente aceptados y que la ideología del directo ha adquirido un grado de 
influencia notable capaz de asentar valores de modo estable en grandes colectivos de audiencias, resulta interesante analizar qué valores de relación con lo real está sembrando el uso del directo.

La ética es, principalmente, un principio de conducta personal. Para que un comportamiento pueda ser ético requiere haber sido seleccionado libremente entre otras opciones y adoptado de modo consciente, es decir, precisa ser responsable (Aranguren, 1996, p. 19) ${ }^{2}$.

Pero las personas somos siempre socialmente responsables. Somos socioculturalmente determinadas en nuestra conducta. Somos hechas por la sociedad en la que vivimos y por el mundo histórico-cultural al que pertenecemos. Señala Aranguren que "el tribunal de la conciencia es, psicogenéticamente, la interiorización del tribunal moral de la comunidad" (Aranguren, 1996, p. 21), que a veces, por cierto, reviste intereses y enmascara prejuicios presentándolos como normas morales.

Por esa razón, la ética repetidamente aplicada en la edición de noticias conforma patrones -sea cual sea la opción que tome--, deviene una ética institucional, ejecutada de modo individual por cada redactor o editor de piezas informativas, pero sostenida de modo colectivo por el medio informativo y por la audiencia que acepta y consume su producto con conformidad.

El sujeto ético que entra en juego es un sujeto social, una fuerza social que viene a objetivarse en una ideología (Aranguren, 1996, p. 37), una constelación de creencias y valores que cristalizan por la aceptación social que alcanzan y que a la vez promueven o reproducen.

El estudio que aquí se presenta persigue elaborar un esquema epistemológico que permita caracterizar éticamente los usos sociales del directo en los programas informativos.

\section{METODOLOGÍA}

Este estudio arranca de una preocupación que surgió en una investigación anterior: detecté una forma de uso del directo que subvertía su lógica: se hablaba en directo de hechos pasados. Se trataba de una noticia del llamado "Caso Mari Luz", un rapto y asesinato de una menor en Huelva, España. En marzo de 2008, una sucesión de errores judiciales permiten que el presunto asesino de la menor esté en libertad a pesar de contar con sentencias condenatorias. El sábado 29 de marzo por la noche, el presidente

2 "Las «normas» o «modelos» de comportamiento y de existencia, conforme a las cuales decidimos «hacer» nuestra vida, han de ser libremente aceptadas por cada uno de nosotros para que el acto y la vida sean morales. Para ello deben pasar, previamente, por el tribunal de nuestra conciencia moral, que las calificará como "deberes»" (Aranguren, 1996, p. 19). 
del Gobierno de España telefonea al padre de la niña asesinada para asegurarle que se investigará hasta el final la cadena de errores judiciales y se depurarán todas las responsabilidades. En el informativo de la noche siguiente de Antena 3 (24 horas más tarde) se realiza una conexión en directo con Huelva. Reporta la información la periodista Tania Losada, desde la calle, una calle desierta y poco iluminada, en la que, a pocos metros detrás de la periodista, se distingue apenas una fachada de un bloque de viviendas y algunos vehículos estacionados. No pasa nada en aquel lugar, el entorno no aporta ningún dato, ninguna evidencia, no muestra nada. La periodista relata lo que, el día anterior, el presidente del Gobierno le dijo al padre de la víctima. Después entran unas colas con imágenes del padre horas antes y más tarde entra un vídeo con una pieza informativa locutada por otra periodista que también empieza su relato en tiempo pasado, recordando lo que el presidente dijo el día antes.

Esta forma de uso del directo la denominé al identificarla directo muerto dado que se usaba para relatar una acción que ya no estaba viva, había muerto. El término servía para identificar un fenómeno, pero no ofrecía caracterización de él, discriminación de las variables que permitiesen apreciar su valor informativo. En aquella investigación, esta labor no era pertinente, se perseguían otros objetivos ${ }^{3}$.

Por tanto, me encuentro con la emergencia de un objeto conceptual paradójico, lo cual abre una cadena de interrogantes: ¿conserva el directo en esas condiciones su valor informativo? ¿Se usa el directo para hablar de lo que ocurre en directo? ¿Cómo afecta al sentido informativo la ruptura de la coincidencia de tiempos (suceso, narración y lectura) que supuestamente el directo ofrece?

Con estas preguntas se abría una veta de investigación plagada de posibilidades interesantes: cómo usan el directo los informativos de las diversas cadenas, y los distintos géneros y programas.

Entre aquella constatación originaria de la existencia del directo muerto y cualquier análisis sistemático sobre su uso se extendía el hueco de la carencia de una herramienta epistemológica apropiada. Se necesitaba tender el puente de la herramienta de análisis que debería permitirnos clasificar distintas categorías de directo, rasgos que las definen, correspondencias narrativas y expresivas de cada uno, etc.

Esa es la tarea que aborda este trabajo: articular la herramienta categorial de observación para estudiar el fenómeno del directo muerto.

Este trabajo, así, adquiere un doble perfil, teórico y empírico: el producto que se persigue es una rejilla de conceptos epistemológicos, diferenciales. ¿De dónde

3 El proyecto estudiaba: La autonomía y el pluralismo de la nueva TVE, a examen: contenidos de los teleinformativos y percepciones de las audiencias. Dirigido por el profesor Juan Pablo Francescutti en la Universidad Rey Juan Carlos. 
sacarla? De la casuística practicada en los informativos. La observación de casos ha de permitir aislar variables estructurales con las que después organizar una clasificación.

Así pues, se aborda un análisis cualitativo de piezas informativas con conexiones en directo que persigue identificar estructuras y rasgos constantes que puedan definir tipos.

¿Qué tipo de observación se requería para este fin? Hacía falta tomar una muestra variada, pero no necesariamente con valor de representación estadística. Hacía falta una muestra intencional que contuviera ejemplares con diversidad de orígenes: informativos de distintas cadenas y de ediciones en diferentes franjas horarias.

Elegí, entonces, un método de análisis cualitativo aplicado sobre una muestra intencional de noticieros de canales de televisión en abierto de cobertura nacional en España. No renuncié por completo a la posibilidad de una estimación cuantitativa marco: en cada uno de los noticieros estudiados, he contabilizado el porcentaje de noticias con conexiones en directo respecto al total de noticias emitidas en esa edición. ¿Por qué?

Porque esa referencia permitiría apreciar la magnitud de la presencia del uso del directo dentro de los temarios diarios, es decir, permitiría tomar una primera medida de la presencia relativa de la técnica del directo en el conjunto de temas de la agenda informativa de cada día. Una medida aproximativa del fenómeno estudiado. Este ha sido el único parámetro en el que he buscado de momento una estimación cuantitativa, por considerarlo un parámetro marco que caracterizaría de modo general el fenómeno que pretendía estudiar.

Más allá de esta referencia marco, la estimación cuantitativa no era objetivo. Será después, en investigaciones posteriores que apliquen la herramienta que aquí presento, cuando la muestra representativa y la medición estadística de rasgos y tipos adquiera valor descriptivo.

He estudiado informativos de televisión durante un mes, desde el 26 de diciembre de 2010 al 29 de enero de 2011. Noticieros de cuatro cadenas de televisión: TVE1, Antena 3, Telecinco y Cuatro.

He analizado el bloque de noticias entre el inicio de los informativos y la ráfaga que da paso a los contenidos deportivos, es decir, el considerado bloque generalista de los telediarios nacionales.

En total he analizado 15 programas informativos, 385 noticias y 51 piezas con conexión en directo.

La clasificación de tipos es el producto perseguido por esta investigación por lo cual se ha aplicado un método inductivo en el análisis de casos particulares para la definición de patrones comunes. Identificar y categorizar la continuidad dentro de la variedad.

De esta manera, el resultado al que conduce el trabajo es un catálogo de arquetipos de directo. Esto se logrará mediante la realización de una investigación 
con las siguientes características: exploratoria, inductiva descriptiva de los esquemas ideológicos de tratamiento del presente aplicables al uso del directo en programas informativos de televisión.

\section{DE LO ÉTICO Y DE LO PATÉTICO}

Lo ético queda definido como aquel proceder que se atiene, con rectitud, a la valoración sostenida socialmente sobre lo que es justo, deseable y bueno.

Sobre lo patético, sabemos por la Real Academia Española, que procede de un término latín (pathetǐcus) que a su vez proviene de otro griego, ( $\pi \alpha \theta \eta \tau \iota \kappa o ́ s) ~ c u y o$ significado es que impresiona, sensible. Lo patético es aquello capaz de mover y agitar el ánimo infundiéndole afectos vehementes, y con particularidad dolor, tristeza o melancolía.

De entrada, entre lo ético y lo patético se abre el abismo del sentimiento individual. Puede cada uno tener su ética, pero es posible definir o identificar conjunto de normas éticas sociales. Sin embargo, el sentimiento patético reside en la insondable soberanía íntima del ánimo.

El sentimiento patético presenta tantas apreciaciones como sujetos puedan experimentarlo. La distinción consignada en el título del trabajo entre directo ético y directo patético apunta pues hacia una valoración subjetiva del uso patético de determinados tipos de directo informativo.

Pero, mientras la estimación de lo patético queda restringida a esa escala subjetiva, el gradiente ético de los distintos tipos de directo informativo podrá ajustarse a una escala de categorías objetivable. Una escala de categorías que marcará los distintos niveles de subversión del sentido del directo.

$\mathrm{O}$, si se prefiere, en un sentido positivo, una escala que mostrará el grado de fidelidad de cada conexión en directo con la coincidencia de los tres tiempos -suceso, narración y lectura-.

Será una escala ética en la medida en que nos permitirá distinguir rasgos con los que la técnica utilizada en cada caso refleje o enmascare la actualidad de los hechos. La ética informativa reclama que la realidad no se enmascare en los informativos. Por tanto, eso es lo deseable.

Desde los primeros códigos de ética informativa en televisión (Matelski, 1992), los elementos susceptibles de generar confusión han sido rechazados. 


\section{IDENTIFICACIÓN DE PARÁMETROS}

La capacidad que tenemos de poder conectar en DIRECTO 4 con cualquier lugar, nos roba el tiempo que deberíamos tomarnos para intentar descifrar el contexto en el que se desarrolla una situación determinada. Eso sucede a menudo cuando se describen incidentes o enfrentamientos violentos. Hace falta explicar tales contextos. También hay que saber distinguir entre la excitación del momento y lo que el público NECESITA ver. Yo sugeriría que la pregunta sobre el empleo de imágenes, antes de tomar una decisión, se formulara siempre así: ¿NECESITAN mis espectadores ver eso para comprender lo que ha ocurrido? (Matelski, 1992, p. 62).

El directo en sí, como recurso expresivo, ha de aportar información y ayudar a esclarecer las condiciones de los hechos objeto de información.

Con esa demanda de fondo, iniciamos la identificación de rasgos observando casos concretos. Un caso es en TVE 1, 26 de diciembre de 2010, 15:00 horas. El primer bloque de noticias, con el que se abre el informativo, va sobre incidencias meteorológicas. Se hacen cuatro conexiones en directo para tratar el tema en diferentes localidades españolas. Se trata solo de temperaturas, no hay nevadas ni riadas. Al final de este bloque, entra la noticia sobre una línea de tren que se ha bloqueado por la nieve en Cantabria, cerca de Reinosa. El bloqueo de vías se produjo a las 8 de la mañana, son las 15:13 horas. El presentador va a dar paso a una conexión en directo con una periodista, Arantxa Blanco, que se encuentra en el lugar, yle da paso con estas palabras: "una odisea que ya ha terminado." ¡Ya ha terminado!”, ha dicho el presentador. Y entra Arantxa en directo. ¿Para contar qué, el presente de lo que está ocurriendo? No, para contar el pasado y además, tras su entrada en plano medio, se divide la pantalla y su plano en directo queda reducido a una ventana pequeña mientras el resto de la pantalla lo ocupan las imágenes de recurso grabadas horas antes, ahora editadas como colas que la voz en directo va cubriendo. Después entra un vídeo con más relato sobre lo mismo elaborado por otra periodista.

Parámetros caracterizadores que se ponen en evidencia:

- El objeto de la noticia: está en curso o está concluido.

- El tratamiento de la noticia: se hace en directo o está editado previamente.

Otro caso: la siguiente noticia de ese informativo, que vuelve a tener directo (en total en este informativo se producen siete conexiones en directo y más de la mitad de ellas sobre el tema hace frío). Esta nueva noticia trata los problemas de retrasos y cancelaciones de vuelos. La unidad móvil está en el aeropuerto de Barajas. Se le da paso y la periodista habla de horarios de vuelos mientras la pantalla se parte: plano reducido de la periodista en directo y resto de pantalla con imágenes editadas del

4 En mayúsculas en el original. 
tráfico en carretera mientas la periodista habla de aviones, irregualaridades en los horarios en aeropuertos españoles y, aunque estamos asistiendo a una conexión en directo desde el aeropuerto madrileño para asuntos nacionales, la periodista pasa a hablar - con las mimas imágenes en colas- de la situación de aeropuertos en EE.UU.y Rusia. Desde el plató el presentador conversa con ella y le pregunta sobre la situación en Reino Unido y Francia. El directo en Madrid se usa para ofrecer información sobre decisiones tomadas por el gobierno británico ("Reino Unido sancionará a las autoridades aeroportuarias") y para hablar de lo que "cuentan hoy los medios franceses” sobre la situación en sus aeropuertos. Un directo, por tanto, desde un lugar (Barajas) para hablar de otros lugares (nada próximos, por cierto). No se acude al escenario de los hechos para documentar, localizar declaraciones de valor local, sino para citar fuentes ajenas a ese escenario y además, fuentes mediáticas. Por tanto, se mencionan fuentes secundarias citables desde cualquier lugar.

La estancia en el supuesto "lugar de los hechos" no es tal: ¿cuáles son los hechos en Barajas, las decisiones del gobierno británico, los problemas de los vehículos en carretera? ¿Cuál es el lugar de los hechos de las decisiones del Gobierno británico, Barajas? El escenario del directo pierde todo sentido informativo. Y, perdido el sentido informativo, resta tan solo el decorativo de puesta en escena.

De esta nueva observación extraemos otros ejes o elementos sobre los que pivota el sentido informativo de un directo y que vienen a unirse al de "objeto en curso o pasado":

- Acción que está pasando

- Lugar en que está pasando

- Fuentes de lo que está pasando

El directo informativo se justifica para acceder a estos elementos. Es por tanto justo, necesario, pertinente, correcto, deseable y ético que se use para eso. Así es como el directo proporciona transparencia en la relación con lo real.

Veamos un caso más: Informativo de Cuatro, el 27 de diciembre, a las 14:00 horas. En total, veinticinco noticias y tres de ellas llevan conexión en directo. Las tres tratan el mismo asunto: el frío, hace frío. La noticia 1, información sobre las heladas de la madrugada; la noticia 2, nieve en Navacerrada; y la noticia 3, nevadas en la costa oeste de Estados Unidos.

La noticia dos es una pura muestra de que la nieve está ahí, en el puerto de Navacerrada. La periodista, Lidia Caamón, cuenta que la gente se divierte jugando con la nieve, es una diversión, las familias disfrutan y los niños se divierten, no dice nada que no sean comentarios previsibles o frases hechas, nada de información. Y a su lado nos muestra un niño en un trineo que está esperándola a ella para que "[ahora] damos un pequeño paseo", dice, y se sienta en el trineo. La fatalidad hace que no se dé cuenta de que lleva el micrófono en la mano. Yo veo como se está colocando con el cable de su micrófono pasado por debajo de su pierna. El niño se dispone a impulsar 
el micrófono, ella sigue sonriente mostrándonos lo contenta que está y el trineo se lanza cuesta abajo por la ladera, jah, que lindo! allá va el trineo, el niño, la periodista y... oh, y el micrófono! El cable se tensa iplaf! la imagen se sacude, el encuadre se gira, el plano se da la vuelta, se oyen ruidos, la cámara va al suelo y la imagen queda en blanco. En directo.

Parámetros: puesta en escena (ruinosa), vacío de información. Directo patético.

\section{CATEGORIZACIÓN}

Las distintas opciones de uso de esos elementos en la técnica del directo pueden articular aproximaciones de grado variable a lo real, grado variable de claridad en esa relación con lo informativo. La variabilidad de ese grado determinará distintas categorías informativas del directo.

Veamos la gama de opciones de respuesta a la pregunta iqué está pasando ahora que (lo) emitimos en directo?

\section{Según la naturaleza de la acción objeto del directo}

Atendemos a la viveza del proceso relatado. ¿Es un proceso en curso o proceso clausurado? (vivo o muerto) La lógica informativa justifica el directo por la necesidad de estar presente durante el desarrollo de los acontecimientos de los que se pretende informar.

Por tanto, podemos encontrarnos con dos situaciones: ocurre algo o no ocurre algo en ese momento:

1. Distinguiremos pues una opción en la que existe un valor informativo directo: asistimos al desarrollo de algo que está ocurriendo en ese momento. El directo, nuestra presencia y actividad informadora en ese momento en ese lugar, nos permite acceder a algo que de otro modo no podría alcanzar el mismo valor y sentido informativo. El acontecimiento está en curso, inconcluso, ocurriendo, nuestra presencia en él garantiza una atención, una alerta que permitirá transmitir al instante las novedades que van produciéndose. Ese es el valor esencial o más puro del directo.

2. En otros casos, nos encontraremos ante una opción en la que solo se pueden dar valores indirectos: nada ocurre, salvo nuestra presencia como reporteros en el lugar. Puede que haya ocurrido antes. Pero el acontecimiento está completado, en ese lugar a esa hora ya no está evolucionando ninguna situación. Ese contexto está muerto informativamente, desactivado. A nuestra actividad como informadores le resta tan solo ocuparse de: 
a. lo ya ocurrido

b. o alguna acción que nosotros mismos promovamos.

¿Cuál es la respuesta en estos dos casos a qué está ocurriendo ahora que emitimos en directo? En el primer caso (lo ya ocurrido) la respuesta es: ocurre la enunciación, lo único que ocurre es nuestra propia acción de nombrar un relato que pretende ser informativo. En el segundo, lo único que ocurre es nuestra propia representación: fabricamos lo noticiable, solo ocurre algo que nosotros mismos hemos preparado, provocamos algo que no existe o no existiría como acción si nosotros periodistas no lo representásemos para mostrarlo, por tanto, no ocurre nada per se, solamente proponemos a los espectadores ser testigos en directo de una acción fabricada, una realidad doblemente producida (el hecho y su relato). La periodista que va a montar en el trineo con el niño en Navacerrada. Somos autores de la realidad (el relato), pero también de lo real (el hecho).

No me estoy refiriendo, no incluyo en esa descripción, actividades propias del reporterismo como la realización de entrevistas. Este tipo de directos que voy a llamar presente artificial, abarca solo esas demostraciones motivadas exclusivamente por la utilidad de dejarlas ver. El show de Navacerrada.

Quedan identificados así según esta primera variable tres naturalezas del objetivo informativo, tres rangos:

1. Ocurre una acción

2. Ocurre la enunciación informativa

3. Ocurre una representación, acción provocada o artificiada por el informador

Cada una de ellas tiene un valor de directo inferior al que le precede según el orden en que las hemos descrito. Categorías de directo derivadas:

1. Presente activo: ocurren los hechos.

2. Presente enunciativo: ocurre la enunciación.

3. Presente artificial: ocurre una pseudoacción o representación.

La ética informativa se debilita a medida que un recurso técnico con sentido para un fin determinado es subvertido mediante su aplicación de fines espurios. El directo de la periodista en la nieve montando en el trineo arrastrando el micrófono y la cámara no solo perdió todo valor ético sino que quedó reducido a puro artificio patético.

Cabría preguntarse si en el caso en que no está ocurriendo nada porque la noticia justamente persigue informarnos de una tranquilidad, nuestro directo está muerto o no. Sin duda alguna la tranquilidad (no acción) en ciertos casos constituye el hecho noticiable, por ejemplo, tras una revuelta social. En casos así, el directo goza de los atributos de aspecto de lo real con pleno sentido informativo que merece ser conocido por la audiencia. En esos casos, la tranquilidad sería un hecho activo, vivo. 


\section{Según el tiempo de la acción}

También podemos imaginar (aunque en ninguno de los ejemplos estudiados se ha dado tal circunstancia) que no esté ocurriendo nada o nada podamos ver en un determinado momento porque el acontecimiento objeto de interés sea el estado de los preparativos. Este supuesto no lo he incluido en ninguna de las categorías ya tratadas porque entrará en una de las que vamos a ver en este nuevo apartado enfocado a categorizar los casos en función de la relación temporal.

¿Qué vínculo puede mantener nuestro presente informativo con el tiempo de los acontecimientos?

Contamos en presente hechos que ocurren en otro tiempo, pero ¿qué relación tiene nuestro presente enunciativo con ese otro tiempo de la acción?

1. Relatamos un pasado que fue y sigue siendo. Presente continuado. Ejemplo: temperaturas, sigue nevando.

2. Relatamos el pasado que ha sido. Presente rememorativo.

3. Relatamos un futuro que se imagina o prevé que será. Presente anticipador o profético. Ejemplo: las temperaturas van a subir.

4. Todos estos supuestos se refieren a casos de directo enunciativo, directos en los que el tiempo presente no aporta desarrollo informativo, novedad. Cada uno de ellos, en el orden en que los he presentado, supone una aplicación del directo más degradada que el que le precede.

\section{Según el escenario de la acción objeto del directo}

Nos fijamos ahora en el parámetro de la ubicación del presente enunciativo: ¿estamos en el lugar en presente para hablar de una acción que tiene o no relación con el lugar en que nos encontramos? ¿Es el lugar fuente informativa?

1. Directoilustrativo. Se acerca a un directo con sentido pleno: la acción destacable ya ha ocurrido, pero el estado del lugar es interesante informativamente en ese momento, es decir, las imágenes de hace horas o de más tarde ya no aportarían una información que en ese momento si es apreciable. Se trata de una situación en evolución y el presente del estado de ese lugar es informativo, aunque la acción haya pasado. Comporta interés la apreciación de un estado que va a ser perecedero, que no era antes y que luego pasará. Ejemplo: una calle tras una manifestación en el momento en que se inicia la limpieza de los residuos en el suelo. Se registra un valor informativo en el estado del escenario.

2. Directo perpetuo: sí hay relación espacial, pero es una relación con un escenario invariable. Es el lugar de los hechos, sin embargo, la acción murió o 
no ha llegado y en presente no ocurre nada en ese lugar que sea informativo, no podemos ver nada que aporte información sobre los hechos relatados. El escenario tiene una significación congelada, una foto fija aportaría la misma información visual aunque careciese de carácter de imagen viva. Ejemplo: la toma de posesión de Artur Mas relatada ante el Palau de la Generalitat de Cataluña tres horas después.

3. Relatamos un presente que se supone, imagina. Presente ausente: está pasando pero no lo podemos ver. Ejemplo: el oficio en memoria de Mari Luz, nosotros a la puerta.

4. Directo arbitrario: hay relación con el espacio, pero esa relación no es necesaria o exclusiva, no es el lugar que documente la fuente de la información, la información no ha sido elaborada gracias a la presencia en ese lugar, se ha ido ahí para presentarla y escenificarla, pero se podría haber hecho igual desde otro sitio, la ubicación es decorativa. Estamos en un lugar para hablar de algo que no ha emanado de esa ubicación, algo que no requiere acudir a ese espacio para ser conocido, y por tanto algo que no hemos conocido gracias a estar allí. Ejemplo: dar las previsiones de las temperaturas para mañana desde una plaza.

5. Directo contrario: estamos en un lugar, pero hablamos de acciones ocurridas en otros lugares. Se distingue del caso anterior, el directo arbitrario, en que, en el caso del directo arbitrario, cualquier otro lugar también sería indiferente pero, en el caso del directo contrario, hay otro lugar que sí sería el adecuado. Un caso: estamos en el aeropuerto de Barajas para contar las cancelaciones de vuelos de Nueva York o las nevadas en Moscú.

También en esta clasificación, el directo presenta un valor informativo decreciente en el orden en el que he presentado las opciones.

\section{Según el rol narrativo}

¿Qué valor estructural se concede al elemento directo en la construcción de la pieza?

Atendiendo a su uso estructural: ¿la conexión en directo constituye la totalidad de la noticia, es el desarrollo principal de la pieza (completada tal vez con un corte de declaraciones) o sirve tan sólo como presentación in situ de una noticia?

1. Directo total (todo es en directo)

2. Directo principal (puede llevar a continuación unas declaraciones grabadas)

3. Presentación (se usa para introducir una noticia grabada y editada antes, un VTR) 


\section{Según la voz directa (fuentes)}

Por último, nos queda desmenuzar una observación respecto a ¿para qué se emplea el directo? Y, ¿quién se dirige en directo a los espectadores? En tan solo dos de las noticias analizadas se ha usado esta técnica para permitir una comunicación de una fuente informativa primaria ajena a la edición del informativo (un afectado en una inundación y personas que van por la calle a comprar en vacaciones de Navidad). Principalmente los periodistas han sido pues la voz informativa de las conexiones en directo. Lo cual refleja un uso de esta técnica exclusivamente al servicio del mediador informativo. Estar en los lugares en presente no ha supuesto un acercamiento menos mediado de los espectadores con lo real. Gracias al directo, la audiencia no ha accedido a fuentes directas en la mayoría de los casos estudiados.

Pero podemos imaginar usos diferentes del directo, por ejemplo: para dar voz a expertos, testigos.

Por tanto, hablaremos de:

a. Directo primario

b. Directo editorial

De los 51 directos estudiados, solo uno era un directo primario.

\section{CONCLUSIONES}

El uso del directo en los espacios informativos no siempre supone un aporte computable en términos de calidad informativa.

El directo supone una forma de producción que puede inscribirse en diferentes estrategias discursivas, en algunas de ellas puede contribuir a desvelar aspectos relevantes de los hechos objeto de información y, gracias a ello, incrementar los valores de transparencia informativa. En otros casos, su empleo deriva en una mera retórica del directo.

En los casos de mera retórica del directo, la puesta en escena del relato informativo se remite a sí misma como objeto de información, no responde al desarrollo de acontecimientos ni contribuye a desvelar aspectos informativos en tiempo real.

La retórica del directo que se consume en informar sobre sí misma provoca una trampa informativa: apariencia de relevancia sobre vacío de contenido. Este trampantojo ${ }^{5}$ informativo genera un bucle para la percepción de la audiencia en el

5 El término designa una técnica pictórica que se concibe como una "trampa ante el ojo" mediante la cual se promueve que la percepción humana extraiga una impresión de realidad de algo, una imagen, que simplemente finge, mediante trucos de inspiración óptica, ser como la realidad. En las artes escénicas el término designa también una puesta en escena o estratagema dramática para hacer creer a alguien que algo es real sin que lo sea, es decir, producir la creencia en una ilusión. 
que es fácil que esta termine confundida. Se sirve a la audiencia la ilusión de algo en sustitución de otro algo que no se da. En ese sentido, los casos de mera retórica del directo se pueden considerar empaquetados informativos para ilusos: sucedáneos con aspecto de información consumibles por audiencias que no reclaman información real, que no pueden distinguir la información real de la que solo lo parece, o que simplemente se entretienen consumiendo productos audiovisuales fabricados con estilo de información.

¿Cuáles son los rasgos que permiten la eficacia de ese trampantojo periodístico? Sobre todo el despliegue de medios de producción informativa, lo que implica una exhibición de recursos. Po un lado, proliferación de perfiles informadores entre los que se va a producir un flujo en cascada de cesión de la palabra: presentador o presentadora en el plató, corresponsales, enviados especiales. Y por otro, capacidad tecnológica de teleconexión con unidades móviles y equipos especiales.

Esta exhibición de recursos produce un rédito informativo (una percepción del capital informativo) impactante: desde una unidad centralizada de control (identificada con el presentador, o con el estudio, la ciudad donde radica el medio o la propia cadena informativa que emite esa información), desde ese nodo central, se manejan distintos y distantes escenarios y personas, datos y testimonios, visión y enfoques. Ese punto, ese nodo deviene referencia central de sentido en la construcción del puzle informativo.

Ese protagonismo ya tiene lugar en la dinámica común del news anchor, conductor o conductora del programa informativo que se presenta como depositario central del poder de ceder la palabra y dirigir la vista a determinados espacios y personas.

Con la retórica del directo la capacidad tentacular de esa figura se incrementa, se subraya y engrandece.

El asunto que habrá que valorar en los estudios de caso y de muestras específicas que se pueden realizar partiendo de la herramienta que aquí he presentado es en qué medida el despliegue tentacular de capital informativo se corresponde con capital de información para la audiencia. ¿La audiencia es cada vez más informada de los hechos o es más informada del poder informativo de quien informa?

La ética de la información exige un empoderamiento de los informados mediante la actividad periodística, dado que ellos y ellas son los sujetos que van a delegar el poder en los representantes políticos, de acuerdo con las reglas del juego que rigen en cada una de las democracias representativas.

Esta delegación del poder que hacen las personas es el fundamento de las obligaciones del periodismo en nuestras sociedades.

La ética de la información pivota sobre esa operación sincera de permitir a quien no llega a todos los rincones de lo real, acceder sin embargo a inputs de conocimiento delo que sucede en todos esos rincones de lo real, y acceder con la mayor transparencia posible. 
Si en lugar de acceso, lo que se hace mediante aparentes acciones informativas es interponer entre la audiencia y esos rincones el artefacto deslumbrante de la propia máquina de informar, entonces, en lugar de transparencia, lo que se hace es obstruir el acceso, quemar la visión por exceso de luz, deslumbrar.

El verbo deslumbrar y el adjetivo deslumbrante tienen una acepción positiva en lengua española: producir una gran impresión con estudiado exceso de lujo. Algo deslumbrante es considerado algo admirable en el uso común.

Resulta admirable por eso que una operación negativa y lesiva (obstruir el acceso a lo que debe ser conocido públicamente) se pueda realizar mediante una acción de matiz positivo: deslumbrante.

Según el diccionario no hay frontera: deslumbrar, dice el RAE es "dejar a alguien confuso o admirado". Según la ética, lo hemos visto, no hay duda: el periodismo no ha de confundir. Las personas deslumbradas, a menudo se quedan ciegas.

Usemos ahora la herramienta de identificación de tipos para investigar en qué medida ocurre y, si es el caso, denunciarlo. Watergate y sus réplicas latinoamericanas pueden intimidar a quien quiera animarse a hacer periodismo de investigación. Sin embargo, este género periodístico no solo ha contribuido a que presidentes renuncien; hay ejemplos que han apuntado a otros objetivos igual de relevantes para las democracias de la región.

TABLAS

TABLA 1

Presencia del directo

\begin{tabular}{|l|l|l|l|l|l|}
\cline { 2 - 6 } \multicolumn{1}{c|}{} & Cuatro & Tele5 & Antena3 & TVE 1 & TOTAL \\
\hline Programas & 3 & 2 & 2 & 8 & $\mathbf{1 5}$ \\
\hline No noticias & 67 & 56 & 50 & 212 & $\mathbf{3 8 5}$ \\
\hline No directos & $\begin{array}{l}8 \\
(2+3+3)\end{array}$ & $\begin{array}{l}6 \\
(3+3)\end{array}$ & $\begin{array}{l}13 \\
(6+7)\end{array}$ & $\begin{array}{l}24 \\
(4+3+1+2+4+2+5+3)\end{array}$ & $\mathbf{5 1}$ \\
\hline \% de directo & $11^{\prime} 9$ & $10^{\prime} 7$ & 26 & $11^{\prime} 3$ & $\mathbf{1 3 , 2}$ \\
\hline
\end{tabular}

Fuente: elaboración propia 
TABLA 2

Tabla taxonómica

\begin{tabular}{|c|c|c|}
\hline Parámetro & Categoría & Descripción \\
\hline \multirow{3}{*}{$\begin{array}{l}\text { Naturaleza } \\
\text { de la acción }\end{array}$} & Directo activo & Ocurre la acción. \\
\hline & Directo enunciativo & Ocurre la enunciación. \\
\hline & Directo artificial & Ocurre una representación. \\
\hline \multirow{3}{*}{$\begin{array}{l}\text { Tiempo } \\
\text { de la acción }\end{array}$} & Directo continuo & Pasado que fue y sigue siendo. \\
\hline & Directo rememorativo & Pasado que ha sido. \\
\hline & Directo profético & Futuro, será. \\
\hline \multirow[t]{5}{*}{$\begin{array}{l}\text { Escenario } \\
\text { del directo }\end{array}$} & Directo ilustrativo & $\begin{array}{l}\text { Un lugar es escenario de hechos y } \\
\text { sus circunstancias presentes portan } \\
\text { información. }\end{array}$ \\
\hline & Directo perpetuo & $\begin{array}{l}\text { Un escenario invariable, puede tener } \\
\text { valor informativo identificativo. }\end{array}$ \\
\hline & $\begin{array}{l}\text { Directo imaginado } \\
\text { (Directo a las puertas) }\end{array}$ & $\begin{array}{l}\text { Se imagina el lugar próximo, no se } \\
\text { puede acceder, es privado o de paso } \\
\text { restringido, pero estamos lo más cerca } \\
\text { posible. }\end{array}$ \\
\hline & Directo arbitrario & $\begin{array}{l}\text { Los hechos podrían contarse desde } \\
\text { otros espacios, no ocurren en espacio } \\
\text { específico. }\end{array}$ \\
\hline & Directo contrario & $\begin{array}{l}\text { No estamos en el lugar del relato y no es } \\
\text { indiferente el lugar porque el espacio de } \\
\text { los hechos sí es otro específico. }\end{array}$ \\
\hline \multirow[t]{3}{*}{$\begin{array}{l}\text { Rol } \\
\text { narrativo }\end{array}$} & Directo total & $\begin{array}{l}\text { Toda la información se ofrece en } \\
\text { directo. }\end{array}$ \\
\hline & Directo principal & Se da información en directo y grabada. \\
\hline & Directo presentación & $\begin{array}{l}\text { El directo simplemente da paso a la } \\
\text { información, segunda presentación. }\end{array}$ \\
\hline \multirow[t]{2}{*}{$\begin{array}{l}\text { Voz } \\
\text { en directo }\end{array}$} & Directo primario & $\begin{array}{l}\text { El lugar permite el acceso a fuentes } \\
\text { primarias, ha ido a su espacio, les deja } \\
\text { la voz. }\end{array}$ \\
\hline & Directo editorial & Habla el periodista, el medio. \\
\hline
\end{tabular}

Fuente: elaboración propia 


\section{Referencias bibliográficas}

Aranguren, J. L. (1996). Ética y política. Madrid: Biblioteca nueva.

Azurmendi Adarraga, A. (2005). De la verdad informativa a la 'información veraz' de la Constitución Española de 1978. Una reflexión sobre la verdad exigible desde el derecho de la información. Comunicación y Sociedad, 18(2), 9-48.

Blanco, J. M. (1999). El directo: análisis de una situación informativa privilegiada (o 'carpe diem'). Revista Latina de Comunicación Social, 19. Obtenido el 15 de diciembre de 2013, desde http://www.ull.es/publicaciones/latina/ a 1999 fil/72bla.htm

Camps Cervera, V. (2008). ¿Todo vale? Hacia una mirada ética en los medios de comunicación. Comunicar, 16(31), 393-395.

Cebrián Herreros, M. (1992). Géneros informativos audiovisuales. Madrid: Ciencia 3.

Dayan, D. (1992). Media Events: The Live Broadcasting of. History. Cambridge: Harvard University Press.

García Castro, M. (2007). La hegemonía creativa de la industria de la televisión. Icono 14, Revista de comunicación y nuevas tecnologías, 9. Obtenido el 15 de diciembre de 2013, desde http://icono14.net/ojs/index.php/icono14/ article/download/374/250

González Requena, J. (2008). Tramas de la verdad. Segovia: Trama y fondo.

González Requena, J. (1998). En el principio fue el verbo. Palabra versus signo. Trama y fondo: revista de cultura, 5, 7-28.

González Requena, J. (1989). El espectáculo informativo. Madrid: Akal.

González Requena,J. (1988). Eldiscurso televisivo: espectáculo dela posmodernidad. Madrid: Cátedra.

Lipovetsky, G. (1990). El imperio de lo efímero. Madrid: Anagrama.

Matelski, M. (1992). Ética en los informativos de televisión. Madrid: IORTV

Mateos Martin, C. (2004). Relatos visibles frente a razones invisibles: un análisis dela pérdida de caudal informativo del periódico a la televisión. Tesis para optar al grado de Doctor, Universidad de La Laguna, San Cristóbal de la Laguna.

Postman, N. (2001). Divertirse hasta morir. El discurso público en la era del «show business $\gg$. Barcelona: Ediciones de la tempestad.

Ramonet, I. (1999). La tiranía de la comunicación. Madrid: Debate.

Sartori, G. (1998). Homo videns. La sociedad teledirigida. Barcelona: Taurus. 